\title{
Tom and Jerry Projecting Violence in Slapstick Comedy: A Qualitative Content Analysis
}

\author{
Md Mohiul Islam \\ University of Malaya, Malaysia \\ mohiul.islamju@gmail.com \\ Hamedi Mohd Adnan \\ University of Malaya, Malaysia \\ hamedi@um.edu.my \\ Mohd Amir Mat Omar \\ University of Malaya, Malaysia \\ amiryangbaik@gmail.com \\ Nilufa Akter \\ City University, Bangladesh \\ nil.mishu@gmail.com
}

\begin{abstract}
This study provides a categorized list of actions that have been termed as violent ones in the famous cartoon Tom and Jerry which has already celebrated its Platinum Jubilee with a lot of allegations for displaying violence. The never-ending rivalry between the cat and the mouse with the slapstick comedy has created some controversies regarding its contents; violence has made the scholars and critics talk about it and its possible impacts on the audience. Apart from lamenting for the impacts of violence on the juveniles' mind, this study rather focuses on how Tom and Jerry projects violence alongside the slapstick comic elements in the name of entertainment, since it is significant to discern what violence is and then categorize them into different types, as different categories of violence may have impacts on the audience in different ways. By defining the term violence, this study shows how Tom and Jerry display the actions which can be the ribs and stretchers of the umbrella known as violence. Whereas most of the scholars concentrate on the outcome of showing violence among the different programs in media, this study categorizes the actions performed by the characters in the cartoon into different categories through a qualitative content analysis method and defines those actions according to the definitions of violence. Defining the actions as violence, this study presents a list of classifications of the violence that Tom and Jerry has been displaying as a slapstick comedy.
\end{abstract}

Keywords: Violence, category, projection, slapstick comedy, entertainment. 


\section{INTRODUCTION}

Since its beginning in 1940, Tom and Jerry has been dominating the watch list of audiences around the globe and also entertaining people of all ages all over the world and as the result, the duo of Tom and Jerry won total seven Academy Awards (also known as the Oscar Award) in the category of best shorts gradually in 1943, 1944, 1945, 1947, 1948, 1952 and 1953 ("Tom and Jerry top cartoon survey", 2004). In the region of entertainment, almost all the genres have some challenges and allegation have some challenges and allegations against themselves for representation and displaying something controversial. Along with the popularity among the viewers around the globe, many of the genres in the field of entertainment have created controversies through the representations and display they have made regarding the issues like sexuality, violence, racial discrimination, political biases and violence. Tom and Jerry is not any exception while they display the never-ending rivalry between a cat and a mouse which started during the era of the Second World War and the Civil Rights Movement in the 1950s. In the storyline of the cartoon, Tom and Jerry unceasingly poke each other which results into a mess in their house with some violent actions although their body and the house also remain the same for the next move (Wells, 1998). Despite having tremendous success as a program of entertainment, Tom and Jerry has created some controversies from its contents for example racially stereotyping the character of Mammy Two shoes, and making some other stereotypical racial representations of the Asians, etc.; and projection of violence is one of those controversial contents, although the creators of Tom and Jerry, William Hanna and Joseph Barbera denied the allegation of projecting violence in the cartoon (Haynes, 1978). This very study concentrates on the projection of violence as content in Tom and Jerry from the qualitative point of view.

In the arena of media violence, many researchers and scholars have contributed to the outcome of the media violence and they mostly focus on physical aggression as one of the most crucial upshots (Bushman \& Anderson, 2001), although for the children indirect social and the relational aggressions are seen as the result of violence shown in media (Martins \& Weaver, 2019). In a study, Martins and Weaver (2019) explain the influence of media on the changes of the children's behaviour which turns towards their relational aggressions. They also explain how it is possible to describe the relationship between the violent media contents and the relational aggressions and behaviour through content analysis studies.Besides, the exposure of different types of violence can have impacts on the audiences in different ways, the exposure of the physical violence may have the 'cross-over' effect on the viewer which ultimately affects the relational skills of the viewers (Coyne et. al., 2008) and according to the theoretical perspective, the this 'cross-over' can function as long-term or can be short-term on the attitudes and behaviour s of the viewers (Martins \& Weaver, 2019). The purpose of this study is not to discuss the probable 'cross-over' effects of the exposure of violence in Tom and Jerry, rather document the depiction of violence in the cartoon. The researchers here attempt to show how Tom and Jerry is depicting different types of violence with different equipment alongside the slapstick comic elements since the variation in violence creates differences in the effect on the children. This study reveals the actions performed by the distinct characters which are legit to be defined as violence. This is a qualitative content analysis study on the exposure of violence in Tom and Jerry where the examples have been poised from the episodes that are strongly containing the elements related to the objective of the study. The researchers have presented an abridged description of certain episodes as they focus only on the issue of violence in the cartoon. And the outcome of the study is a category of the actions performed by various characters in Tom and Jerry which can be defined as violence. 


\section{SLAPSTICK COMEDY}

As it has been mentioned that, Tom and Jerry has called itself a slapstick comedy, the authors here have found it significant to discuss and clarify the slapstick comedy since the cartoon itself defended the allegation of the projection of violence by defining itself as a slapstick comedy. In the paradigm of visual media, comedy or comic elements are mainly watched to release the stress that human minds gather from everyday life. In terms of literature, comedy is a genre where the story ends with a happy moment when all the characters are happy and the as well as the readers too. It does not create any sort of negative feeling in the mind of the readers. Rather it creates laughter among the readers. Gradually this laughter makes the audience happy and help them in releasing the stress they possess.

In case of the visual entertainment, the functions of the programs from the comedy genre are similar to the comedy in literature. The readers become the viewers, and the rest of the chemistry between the readers and the program remains the same. The viewers, after watching a comedy show, go back to their home with a happy mind, releasing their stresses. In programs with serious plots, the plot-maker keeps some comic elements for the viewers to removes the seriousness and the stress from the minds of the viewers. These comic scenes or elements are sometimes made by creating some silly incidents involving sometimes the protagonists and sometimes some other characters where they may face some physical occurrences rather than the funny and comic dialogues, which are not harmful to them, but only make the situation funny.

Slapstick comedy is one of the types of comic elements or the genre of comedy that is used in visual media entertainment. As the focus of the research, Tom and Jerry is best known as a slapstick comedy, it is quite significant to have a clear understanding of the structure and functions of a slapstick comedy. Usually used in programs for visual entertainment, the idea of slapstick comedy comes from the term slapstick which refers to a trick of using two pieces of wood that are attached to each other at one end of them. While being used in hitting a person, this wooden device makes noise and makes the hit noisier which creates an audial expression of a forceful hit (Slapstick, 2010). Initially, slapstick was used in the films during the fight scenes. In the film, when someone hits or slaps another, by using the slapstick, the hit was made more forceful by its sound. It was the silent era of American films where the slapsticks had been used initially, as during the very first days of cinema, American cinema could hardly contain comic subjects and thus they could not bring laughter among the audience. Peacock (2014) citing Scott (2005) elaborates that, slapstick is generally accepted as a vigorous and hyperbolized physical comedy in which tricks, manoeuvres, discomfort and aggression are typical characteristics. Since Aristophanes, wide comedy of this sort has been there, however, genre recognized as slapstick emerged into being in early American Cinema as basically the sole comedic circumstance.

In the paradigm of visual entertainment, slapstick refers to a type of comedy or comic action which has a strong relation with the physique of the characters involved in the slapstick comedy scene. Hence, slapstick comedy derives from the comical physical action performed by the characters involved in it (Kirsh, 2012). The slapstick actions may include pushing or closing the doors on the face, hitting on the head with a hammer, or even poking on to someone's eyes, stepping on the banana peel and getting slipped, getting injured through an accident etc. In most cases, slapsticks are used funnily or comically to create some comical moment to remove the boredom of the viewers during the film or drama. It gives a comic relief to the viewers who have been watching the serious actions for a long 
time. In this regard, slapsticks become more a comedy rather than some serious visualization of injurious actions. Paul Wells' definition of slapsticks directly creates the bridge between the slapsticks and comical action. According to Paul Wells, slapstick is a type of comic tools which is harmless and inoffensive for the characters involved in it, but it also brings a sort of "destabilization and disorder" for them too (Wells, 1998, p. 102). The slapstick comedy is not only used in films but also used in cartoons and animated films which are made for children and teenagers, as the slapstick comedy does not visualize any serious or fatal injuries to its viewers, rather it depicts the accidents (sometimes) and other actions (the slapsticks ones) in a comical way so that those can create laughter among the viewers.

While defining the description of the slapstick actions, Bruner and Postman (1949) have found a relation between the action and the scientific laws or reasons. According to Bruner and Postman, the scientific laws can be overlooked while creating a slapstick action in the cartoons. For an instance, they mention about the law of gravity, which is hardly maintained in the cartoons where the actions are displayed as slapsticks one where the unscientific actions are displayed to create laughter among the viewers. According to Bromley (2019), slapstick comedy is more actions than dialogues. This sort of comedy is known as "physical comedy,". To display a slapstick comedy in a visual entertainment program, it requires great timing, animated facial expressions, and quite a bit of acrobatics to pull off.

\section{LITERATURE REVIEW}

This part of the study discusses the definitions of violence from different perspectives with different categories of it in media since this study focuses on the media contents only. By stating different categories of violence in media, the authors here also discuss how American cartoons have been accused for projecting violence which is followed by some of the criticisms made on and for Tom and Jerry by the scholars, critics and also one of the directors of the cartoon regarding the violence controversy of Tom and Jerry.

The meaning of violence in media is not constant, rather it is much more contextual to many people and researchers. Many studies have already been conducted to figure out the definition of violence and its portrayals among the media contents in various programs. Based on the target viewers, the same actions can be called violence, and sometimes as non-violent funny actions or slapsticks actions. Besides, the type or state of the performers also defines the actions as violent or not. From the studies of the past researches on violence, Hargrave (in Feilitzen \& Carlson, 2000) outlines violence as an action which is an interpersonal issue and which is sometimes defined from their perspective along with the context; and he also agrees with the previous researchers regarding defining the term violence as an act that breaks any recognized code of behaviour. Withal, Hargrave also mentions that, the researchers have found some issues of arguments regarding seeing an action as a violent one when the viewer analyzes the character whose action is under the spotlight to be called as violence, hence the argument turns into confusion when the action is performed by a character who has an unclear portrayal as a good or bad character to the viewers (Feilitzen \& Carloson, 2000). Although, according to a very old study on the violence and children content in media by Howitt and Cumberbatch in 1975, most humorous cartoons should not be considered as violent to the adult viewers (Kirsh, 2012). On the other hand, according to Potter (1999), the definition of the term violence depends on what are the actions that the viewers perceive as violent acts, the viewers can have a long list of violent acts and can shorten the list by being 
restrictive while making the list and researchers around the globe have used several terms to synonymize violence, such as aggression, conflict, crime, and antisocial behaviour, etc. He defines violence as a set of behaviours or actions through which one character can cause harm to another both intentionally and accidentally.

Bandura (1973) referred violence as an act of behaviour where one person intends to hurt another with a firearm or by striking him/her with a lethal weapon. Berkowitz (1993) has added the dispute of psychological injury along with the physical damage that Bandura mentioned to define violence, whereas, Gunter's (1985) explanation on violence focuses on the intensity, momentousness someone to hurt another. But Potter (1999) has recommended the most acceptable and widely used definition of violence in content analysis studies stated by Gerbner and his fellow scholars and their definition became a standard to code for a content analysis focusing on violence.

From the discussion above, the term violence can be defined as an act which is or has been performed by the characters where the characters may have some interpersonal issues for which they intend to harm each other both physically and mentally by using some lethal weapons or even by using some tools or equipment from the everyday life and household stuffs or even by bullying others. The authors here seek how the characters in Tom and Jerry intend to harm each other since this cartoon is based on an endless rivalry between the cat and the mouse. While scrutinizing the actions that can be regarded as violent ones, the researchers here have overlooked the characters for example which is the protagonist, which one is the villain, which character is the antagonist, rather the authors have focused on the acts only and the equipment and tools the characters used to hurt each other.

According to the research findings of David Morrison (in Feilitzen \& Carlson, 2000), the respondents in Morrison's study classified the violence in the media contents based on what they had witnessed and experienced in their real life. So, basing on the respondent's opinions and arguments, the researchers in Morrison's study on media violence, have categorized the violence into three categories. Firstly, the playful violence which sounds unreal and recognized as entertainment only rather than graphic, secondly depicted violence, which is more realistic and graphic and finally, the authentic violence, which is set within the content and the domestic violence are into this category.

Moreover, in the study done by Feilitzen and Carlson (2000), it is found that the audience finds the violence depicted in the media contents are different from the violence they experience in their real life. Therefore, Feilitzen and Carlson have categorized violence into two types: fictional violence and factual violence. The nature of the offender, the nature of the target, presence of a weapon, reason of violence, range of depiction, the realism of the violence, rewards and punishment for the violence, and its consequences are the key facts of the fictional violence; whereas the factor of closeness, the issue of certainty, the factor of the degree of violence and the factor of minimalism are the key factors of the factual violence found among the media contents. They have also opined that fictional violence is more stressful than factual ones to the audience (Feilitzen \& Carlson, 2000).

Although the term, 'cartoon' sounds very much comedic, violence has been considered as one of the intrinsic contents of the cartoon since its beginning (Kirsh, 2012). From the study conducted by Beckman (1997) during the end of the twentieth century, it is found that, in a third world country like the USA, children watch television for more than 28 hours per week and they watch nearly 8000 murders before they are even 12 years of old. Moreover, 
Potter and Warren (1998), from their study, have instituted that the depiction of violence is maximum in the cartoon shows with the presence of some minor acts of violence, gore and rapes never shown. However, victims of the violence in the cartoon hardly shown suffering in pain by sensitizing the violent contents and the overall consequence remains generally very delicate and nonthreatening (Klein \& Shiffman, 2008).

Feilitzer and Carlson (2000) have argued that sometimes, more intense violence adds more value to the storyline of the cartoon; for a detailed study on the violence in the cartoons, they have sorted the cartoons into four brands. The first brand is the means or weapons used in the violent scene; the second one is the production elements of the incidents, and the third brand is the presence and absence of humour and finally, the fourth brand is the immediate reactions and intentions with aggressions of the characters.

Haynes (1978) has studied two more types of cartoons containing violent contents which are known as the 'Authentic' cartoon where the characters and monsters have the authentic and real-life look and the 'Comic' cartoon where the authentic-looking characters are substituted by the comical characters and attributes such as Tom and Jerry, Road Runner, Woody Wood Pecker. Haynes has also illustrated that having real-life looking characters and attributes, the authentic cartoon contain such elements as, threats to life or physical injury and death as a consequence; on the other hand, comic cartoon is quite opposite where death is hardly shown and characters get themselves back in the actual shape after a huge knock of injury or violence. From his study on comic cartoon, Haynes outlined the comic cartoons more violent than authentic cartoon where violence itself performs as the main plot and creates glee for the audiences.

Tom and Jerry has been on the top list with immense popularity among the children as well as the adults since its beginning. According to a survey report published in BBC News in 2004, Tom and Jerry was in the first position in the list of the most popular cartoons around the globe (Tom and Jerry top cartoon survey, 2004). It has also occupied the third position in the list of the best cartoons of all time made by the RANKERS (The Best Cartoons of All Time, n.d.) But along with its massive popularity, Tom and Jerry has given birth to some controversies regarding a few issues such as the racial portrayal of the characters, usage of colours in portraying the characters, stereotyping the villain and heroine through colours (Islam et al, 2020), where the portrayal of violence is one of the talks of the topics. For many social scientists and researchers, Tom and Jerry would be considered very violent due to its contents and projection of violence (Potter, 1999).

Haynes (1978) in his study on the comic and authentic cartoons, has mentioned Bill Hanna's (from the Hanna-Barbera Production of Tom and Jerry) opinion regarding the portrayal of violence in Tom and Jerry. William Bill Hanna, one of the most prominent directors of Tom and Jerry, never wanted to call the cartoon a violent one. Rather he defended this allegation had been brought against Tom and Jerry. According to Hanna, the actions in the cartoon that are called violence, are only for comedy rather than promoting the violence itself. Haynes has also mentioned the argument made by Dr. Margret McFarland, the psychological consultant for "Mister Rogers Neighborhood", regarding portraying the violence in slapstick comedy and comic cartoons like Tom and Jerry. Dr. Margret has strongly opposed the way of portraying the violence in the cartoons in a comedic way. Potter (1999), in his study On Media Violence has mentioned the concerns of the social scientists regarding the issue of violence in Tom and Jerry. According to Potter's statement, Tom and Jerry contains so much violence 
and the violence are sanitized and desensitized to the people so that people do not concern about the projection of violence in the cartoon (1999,).

Morrison (1993) directly raised fingers towards showing violence in Tom and Jerry and he strongly argued that, if the violent scenes were cut off from the cartoon, there would have been nothing left to show for entertaining the audiences!

The recent most allegation against Tom and Jerry regarding its projection of violence has come from Seham Hassan, a professor of Psychiatry at Cairo University. In her latest interview with Nogoum FM, Psychiatrist Seham Hassan claimed that along with some video games, Tom and Jerry can have a negative impact on the psychology and behaviour of the children due to its projection violence (Essawy, 4 December 2018).

Brion (1990), while discussing the issue of sexuality in Tom and Jerry, up brings the point of violence in it. In his discussion on the sexuality in Tom and Jerry, Brion says that Tom and Jerry have a very mysterious relation between themselves which vacillates between hostility and friendship; there is game they play and their game turns into violence. Brion also says that after all the violence and numbers of explosions from dynamite sticks and bombs, they remain the same as before, with their same appearance!

Tom and Jerry is quite popular in the Middle East and is routinely transmitted to effective and scorching conflict areas, particularly Iraq, through satellite channels. An Egyptian physician and self-described researcher also said that Walt Disney borrowed the concept from the ancient Egyptians (Johnson, 2016). The latest statement by Ambassador Salah Abdel Sadek, president of the Egyptian State Information Service, has accused the iconic Hanna-Barbera cartoon, Tom and Jerry, for the disturbing abuse and terrorism in the Middle East nowadays. At a Cairo University conference entitled "Media and the Culture of Violence," Ambassador Sadek said that the cartoon "portrays the violence in a funny manner and sends the message that, yes, I can hit him ... and I can blow him up with explosives. It becomes set in mind that this is natural." The program, which is frequently transmitted throughout the Middle East, including in insurgent regions, has habituated new generation of young people to violence, as per Sadek, and is partly responsible for terrorism in the zone. Egypt's privately owned Youm 7 newspaper, citing Sadek's statement, illustrated why Tom and Jerry are causing terrorist acts: reportedly, it adapts children to unhealthy habits, like cigarettes, consuming alcohol, and attempting to steal; illustrates an imbalanced sense of morality wherein the mouse is usually right; incorporates "sinister plans" concepts into kid's influenceable psyches; and promotes violence via its representations of knife and axe assaults (McCabe, 2016, Johnson 2016). However, Johnson has opined that, in the cartoon, Tom and Jerry have never been active in murdering one another, and their efforts to do so are typically backfired. One may argue that it demonstrates that aggression not only doesn't function but also causes more damage than benefit to those who use it.

It is quite obvious that Tom and Jerry has created some major controversies through its contents where projecting violence is one of the talks of the issues. Scholars, bloggers, researchers, and even policymakers have talked about it and the directors have tried to defend Tom and Jerry from the accusation made regarding promoting violence. However, none of them has spoken about how Tom and Jerry is displaying violence in the name of slapstick comedy or which actions in the cartoon can be termed as violent ones, the scholars so far only emphasized the possible aftermath of projecting the violent scenes through a comedic way. The reception and the cultivation theories can be applied while analyzing the 
impact of watching media violence on children. The paper does not discuss violence under any theoretical proposition. Rather it only specifies the actions performed by the different characters in Tom and Jerry that can be scrutinized as violence considering various definitions of violence and it is significant to study any issue with proper scrutiny before going for the aftermath of it. The current study just identifies the actions and put those into the frame of violence which ultimately proves how Tom and Jerry has been displaying violence in the name of slapstick comedy. In other words, this paper examines the actions performed by the various characters in Tom and Jerry under the light of the definition of violence.

\section{METHODOLOGY}

This study is conducted by adopting the qualitative method in the attempt to show how Tom and Jerry is displaying violence in the name of slapstick comedy. The study does not intend to focus on how many violent scenes are projected in Tom and Jerry rather, how this cartoon is promoting violence through the projection of the numerous violent acts. Moreover, a qualitative study helps the researchers understand the human experiences and social phenomenon in easier ways rather than a quantitative study on the same issue and the authors here have adopted the qualitative content analysis technique since this approach eases the discovery for the researchers to find out the meanings of the messages conveyed directly and indirectly by the various contents of the media (Priest, 2010).

To achieve the goal of the study, qualitative content analysis was used as the primary method for this study since it helps the researchers to discover the meanings of the messages that are more generalized in nature (Priest, 2010) in conjunction with the denotative and connotative ideas of the messages conveyed the contents of the media (Krippendorff, 2004, p. 18). The content analysis approach is one of the most widely used techniques in doing media research along with its ability to analyze human behaviour explaining the different characters and their action in different media like TV, comic strips, videogames, cinemas and so on (Berger, 2014).

Krippendorff (2004, p. 18) regards content analysis as a systematic process to decode the messages in media and communication and for this study, the authors have taken the TCA (Traditional Content Analysis) approach which Kippendorff (1980) described in his study with the following steps for the study:

- Foundation of the research question/s

- Selection of the sample

- Categorizing for coding

- Reliability check for the coding

- Analysis and interpretations of data collected during coding.

Considering the literature, data and state of the study, the qualitative content analysis has been adopted to conduct the study since it provides the researchers with some opportunities to overcome the limitation of having less literature and data along with the opportunity to analyze the target content in a precise way (Sparks, 2010).

Although content analysis research can be conducted both in inductive and deductive ways, yet it is the nature and objective of the study that decides which one to be implemented in a study (Elo \& Kyngas, 2008). Since the data and literature on Tom and Jerry is outnumbered 
and fragmented, the inductive approach would be the most appropriate to conduct this certain study (Lauri \& Kyngas, 2005). Moreover, the inductive approach makes the study more generalized from specific (Chinn \& Kramer, 1999), hence through the inductive category development approach, this study presents a generalized description of how Tom and Jerry is projecting violence in different episodes.

According to the study of Fields (in Berg \& Lune, 2014), while conducting a content analysis study, the researchers get the options to appoint the unit of analysis that is more admissible and significant to the focus of the study. Hence, the researchers of this study single out only the violent actions depicted in Tom and Jerry as the unit for the analysis. As this is an inductive approach of the content analysis research, the authors first have categorized the qualitative data inclusive of the open coding by developing categories, generic categories and subcategories according to the study of Elo and Kyngas (2008).

For this study, violence is the only category to analyze which has three generic categories as violence by using firearms, by using cutting tools and hitting on the body with anything. According to the study by Potter and Ware (1987) on violence, there are two levels of violence in media, physical level and symbolic level of violence. The physical level includes the destruction of any property, burglary, larceny, robbery, assault with or without a weapon, rape, and murder. On the other hand, symbolic violence covers the spectrum of minor deceit, insulting someone through jokes, hurting someone's personal choice, threat to loss reputation, nonverbal threat to someone to loss the life or money, etc.

After specifying the unit to analyze, attention was given to the coding agenda, which is to categorize the unit into apposite clusters which describe the unit chosen for the study along with the findings. For conducting a qualitative content analysis on Tom and Jerry, categories were developed and the coding agenda on the depiction of violence in Tom and Jerry was prepared. The coding agenda suggested by Mayring (2004) for a qualitative content analysis research study was adopted.

The coding sheet is considered as one of the major components for a qualitative content analysis study of any media content. For this very study, the coding sheet is prepared to keep the rations of a qualitative content analysis research in conjunction with the objective of the study. The coding has been done from the descriptions of the sample episodes. From the video to the open codes, and finally to the theme, the entire process of coding has been displayed through the following figure. From the open codes, the researcher has gone for categorizing them into different categories and subcategories from where the themes are being established.

To maintain the validity of the coding as well as the study, intercoder reliability was used for the current study. First of all, the descriptions of the sample episodes have been checked rigorously by the authors and other experts in the field, so that the source of the codes remains most vivid and full of information. Next, the authors confirmed the coding with an aim to keep the codes reliable and valid for the study. Therefore, the authors completed coding process by three different coders and selected only those codes that were common among all the codes selected by the three coders. The following figure (Figure 1) shows the Ven-diagram of the intercoder reliability for the study. 

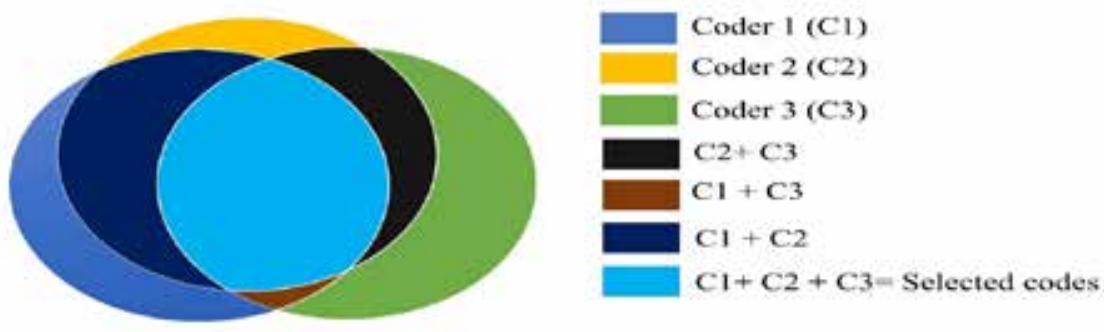

Figure 1: Intercoder reliability of the study.

For this study, purposive sampling was adopted. Only those elements as the sample match with what the researchers are having in mind were selected to accomplish their objective of the study and it also associates the interest of the researchers along with the proper utilization of the materials available for the research (Etikan, Musa, \& Alkassim, 2016). The researchers have only picked those episodes which contain evidence necessary to support the objective of the study as a qualitative approach of content analysis does not need samples with statistical validities and formulated data (McNamara, 2005). The study focuses only on the first series (also known as the originals) of Tom and Jerry which includes the episodes produced from 1940 to 1967. In total 161 episodes were created during the classic era of Tom and Jerry. The researchers have preferred those episodes which are rich in information to make the best use of available resources that is the episodes that have more evidence related to the objective of the study since the sampling process in a qualitative approach are more connected to the research questions and objectives (Miles \& Huberman, 1994).

Considering the variations of the directors, Maximum Variation Sampling (MVS) approach was used so that the study covers all the directors' episodes made between 1940 and 1967. The MVS process ensures that episodes have been taken from all the directors' productions. Moreover, the MVS process of sampling has also confirmed the authors about the presence of the maximum of the characters in the episodes. Hence, the authors here have chosen such episodes for the study so that the authors have the option to cover the presence of the maximum number of the characters in Tom and Jerry cartoon produced between 1940 and 1967. In total 21 of the 161 episodes has been chosen for the current study. The episodes are, Fraiday Cat (1942), Puss n' Toots (1942), Baby Puss (1943), The Zoot Cat (1944), The Mouse Comes to Dinner (1945), Spring Time for Thomas (1946), Trap Happy (1946), Solid Serenade (1946), Sal Water Tabby (1947), A Mouse in the House (1947), Truce Hurts (1948), Tennis Chumps (1949), Saturday Evening Puss (1950), Texas Tom (1950), Casanova Cat (1951), Jerry's Cousin (1951), Baby Butch (1954), Muscle Beach Tom (1956), Blue Cat Blues (1956), Calypso Cat (1962), and Love Me, Love My Cat (1966). To avoid the complexity of and the extra length of the study, the authors here have described the episodes A Mouse in the House (1947) directed by William Hanna and Joseph Barbera, Calypso Cat (1962) by Gene Deitch, and Love Me, Love My Cat (1966) by Chuck Jones.

Regarding sampling the episodes, the researchers have applied the Homogeneous Sampling process of purposive sampling which deals the samples only related to one issue. The data has been collected from the DVD on Tom and Jerry available in the stores to purchase. Particular scenes related to the objective of the study, have been extracted from the videos form various episodes of Tom and Jerry original series directed by different directors. Since 
there is no verbal data that can be gathered from the cartoon, the detailed description of the actions performed by the characters has been analyzed. Hence, the descriptions of the episodes have been made and from the descriptions, the actions have been sorted out through $\mathrm{N}-$ Vivo 12 plus, which are the data for the study. Therefore, the descriptions of the episodes are data source for the current study.

\section{PROJECTION OF VIOLENCE IN TOM AND JERRY}

After being created in 1940, Tom and Jerry is still occupying a place in the watch list of millions of people and children around the globe with its slapstick comic elements with comic fights in the same storyline almost in every episode. And these fights bring violence in front of the audience.

Tom always tries to keep his house free from Jerry and sometimes he tries such because his house owner wants it so and sometimes, he does it by his own will. But every time either when Tom chases Jerry or when Jerry tries to save his own life from the hands of Tom, they both attempts to hurt each other and sometimes even do something which may get both Tom and Jerry killed. Although, no portrayal of graphic signs and blood shade is found in any of the episodes of Tom and Jerry made by different directors. Besides Tom and Jerry, when there are presences of other characters like, Butch the cat, Spyke, Tyke, Nibbbles, Toodles Galore in Tom and Jerry, they are also found doing something which might hurt others.

In William Hanna and Joseph Barbera's A Mouse in the House (1947) Tom gets a company of Butch the cat and they both are asked by the maid of the house to keep the house free from the mouse and they set themselves on duty. But the problem occurs when they both want to catch the same mouse, Jerry. Just be the hero in the eyes of their owner, both Tom and Butch starts trying to capture Jerry. They start making plans and execute those. In consequence, instead of capturing Jerry, they become their own contender. Jerry also takes chance here by hitting Butch's toe with a piece of wood and both Tom and Butch decide to have duel raw between themselves. Whoever wins, will be in charge of catching Jerry but eventually, this attempt gets failed and their conflict remains as it is. Once, when both Tom and Butch looked for Jerry inside the oven stove, Jerry made a plan to get rid of the two cats and set the oven stove on fire. The situation gets worst when both Tom and Butch disguise as Mammy Two Shoes, the housemaid and hits each other with the housing hold stuff and finally they both start beating the maid assuming that she is not the real Mammy Two Shoes.

The Calypso Cat (1962) by Gene Deitch, starts with Tom chasing Jerry on a ship namely the Caribbean Queen starting for the Caribbean Islands. Tom runs to catch Jerry with a big thick piece of rope and suddenly Tom gets hit on his head by the heavy bowling ball. While running after Jerry on the ship, Tom again meets Toodles Galore, his beloved white female cat and becomes busy impressing Toodles in many ways which Jerry does not like. As Tom has never been able to win the heart of Toodles Galore, Jerry now tries to take Tom's attention away from Toodles and he sets Tom's foot on fire (Figure 6) which ultimately makes no effect on Tom! And Tom continues trying many things to win the heart of Toodles Galore. After getting down from the ship, Tom, Jerry and Toodles meet the Caribbean Calypso cat, who appears as a musician and plays the drums with Caribbean music. Eventually, the Calypso Cat and Tom become enemy to each other regarding impressing Toodles Galore and they even forget the presence of Jerry. At one time when the Calypso cat and Tom are having a confrontation, the Calypso cat beats Tom with his drums in front of Toodles and Jerry. 
Chuck Jones' Love Me, Love My Cat (1966) begins with Tom preparing himself to meet his beloved Toodles Galore and this time he has a gift for her, Jerry in the box. So, Tom has already captured Jerry and he gives it to Toodles Galore. But for some reasons, Toodles doesn't want to eat Jerry and whenever Tom tries to eat Jerry, Toodles comes ahead and saves Jerry and hit Tom, sometimes with plate, sometimes with cooking pot. Since, Toodles Galore doesn't want Tom eat Jerry and she beats Tom quite a number of times, Jerry intentionally makes some tricks so that it seems Tom wants to eat Jerry alive and then get hit by Toodles as punishment. At the end of this episode, Tom sets a trap with heavy iron to kill Jerry which falls on to Tom and Toodles Galore finally brings out the knife and fork to kill Jerry.

Apart from these, there are a lot more episodes where the characters in Tom and Jerry are seen committing some actions which can be regarded as violent ones from almost every aspect of violence. They are seen attacking each other with different weapons, machinery and tools from daily life. Sometimes the characters are in such a situation that they forget their own identity and become enemy of their friend and friend of their enemy. The cat attacks the cat, the mouse helps the cats to attack the other cat. They use bombs, guns and firearms, household stuff, farming tools, sports equipment, and musical instruments either to attack others or to ensure their safety. Although these actions seem more playful violence according to David Morrison's (in Feilitzen \& Carlson, 2000, p. 249) research on violence, since in Tom and Jerry audience can never witness any graphic portrayal rather the actions and violence are shown in more comedic ways even though sometimes the characters get hit hard on their head, get shot by guns, get slashed by swords and knives, they get their tail cut and finally they get themselves healed.

From the very beginning of Tom and Jerry, the plots of the episodes are the same in maximum cases where Tom attempts to capture Jerry and on many occasions, these attempts turn into the attempts to kill Jerry. And unfortunately, most of the times, success does not come to Tom. He fails to catch Jerry which makes him even more desperate towards Jerry. Usually, Tom is seen chasing Jerry with bare hands. But the failure of catching Jerry with bare hands makes Tom using various weapons ranging from household kitchen stuff to firearms to catch Jerry and sometimes he wants to kill Jerry. But nothing brings the success of capturing Jerry or sometimes the death of Jerry. On the other hand, it is Jerry's cunningness that always helps him to get rid of Tom. It is not only Tom who attacks Jerry, sometimes Jerry is also seen attacking Tom with weapons that are far more violent than those of Tom's ones. In terms of Tom's action towards Jerry, Jerry is found more successful than Tom with much more violence. Using firearms, knives, matchsticks and fire, firecrackers, fireworks, bombs, maces, cooking stuff, electric shocks are very common in Jerry's retaliation towards Tom.

And it is not only Tom and Jerry who attacks each other violently, there are some accidents also which are violent in nature. Sometimes even the minor character in the shorts, like the owner of Tom also hurts Tom brutally with kitchen tools, or sometimes with some other machinery.

\section{DISCUSSION AND ANALYSIS: PROJECTION OF VIOLENCE}

The computerized analysis of the description of the selected episodes of Tom and Jerry give the following word cloud (Figure 2) of violence from where it becomes easier to understand the projection of violence which takes to the word tree (Figure 3) that relates the violence and the actions performed by the characters in Tom and Jerry. 


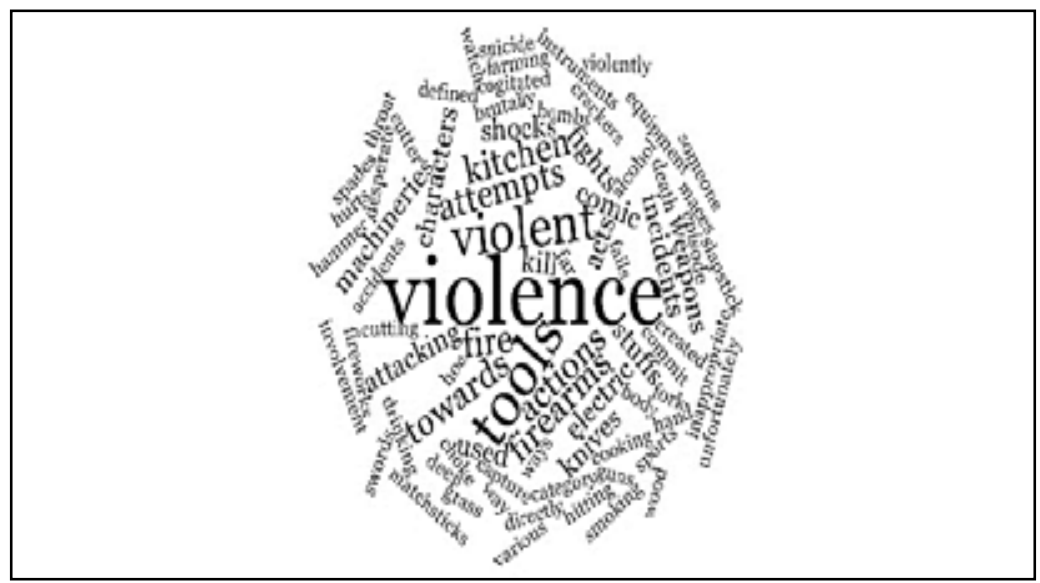

Figure 2: The word cloud of violence in the description of Tom and Jerry.

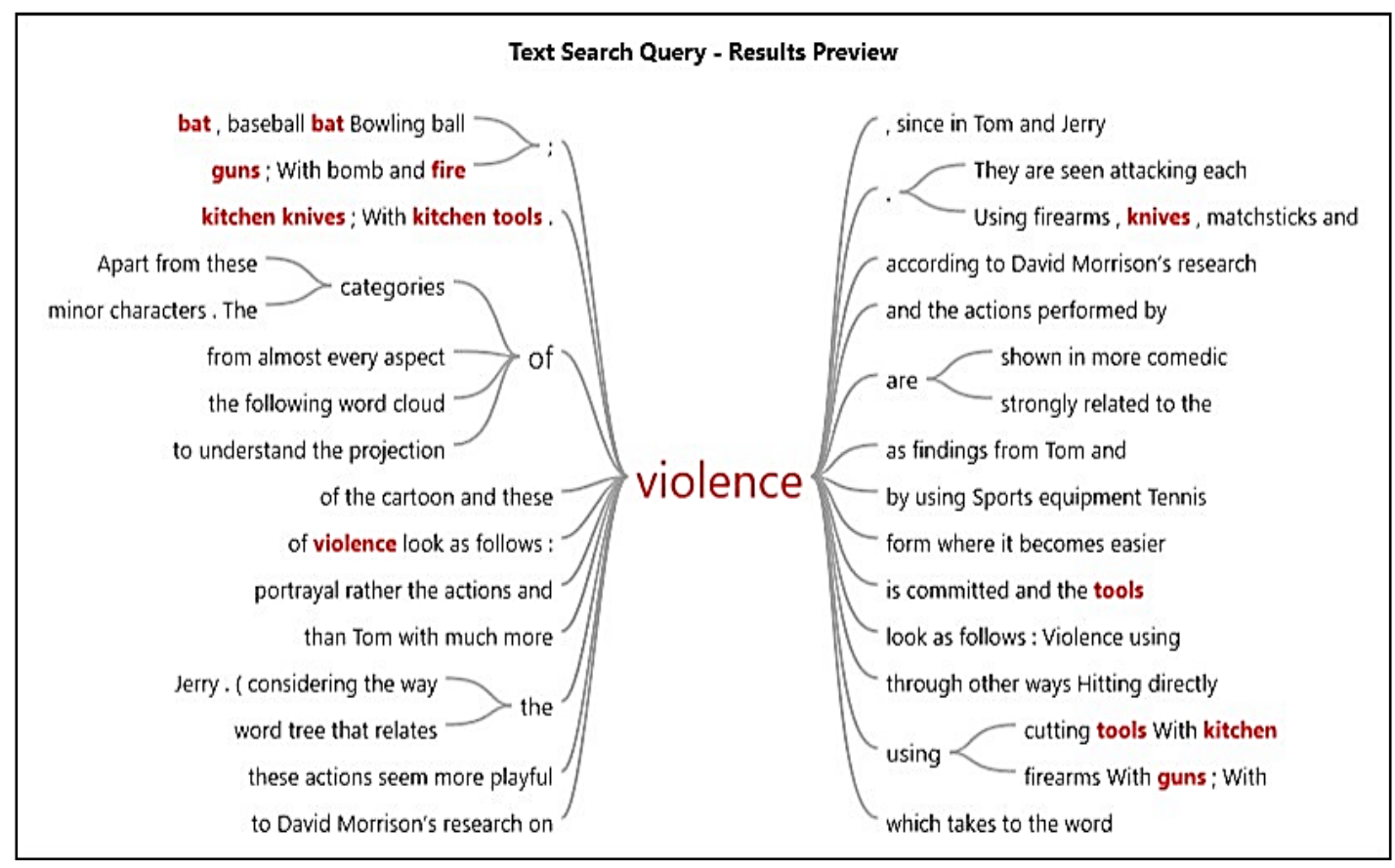

Figure 3: The Word Tree of violence and actions in Tom and Jerry.

From the analysis done on certain episodes of Tom and Jerry, the researchers here have found mostly three deep-seated types of violence (considering the way the violence is committed and the tools that have been used to commit) present in the episodes of the cartoon and this violence are strongly related to the main storyline of each episode, which if left out or excluded, there would not be much things and incidents to entertain the audience. Each category has also subcategories based on the uses of the tools or instruments the characters have used. Most of the violent incidents are predominantly related to the plot of the story and actions done by either Tom or Jerry, along with the involvement of some other minor characters. Figure 4 demonstrates the categories of violence found in Tom and Jerry. 


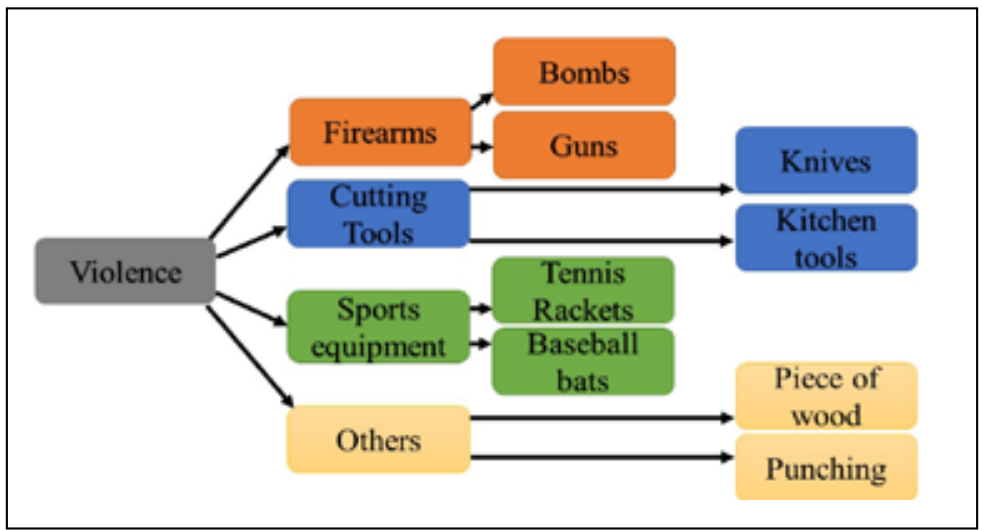

Figure 4: Categories of violence in Tom and Jerry.

Apart from those categories of violence as findings from Tom and Jerry, there are some other actions found that can be defined as violent acts and inappropriate for the juvenile audiences, such as getting electric shocks; drinking alcohol; smoking; disturbing a dog; attacking someone with the grass-cutter; using farming tools like fork hoe, spades. There are episodes also where Tom is seen to choke his own throat and kill himself and there are episodes where both Tom and Jerry go for committing suicide. All these actions projected in Tom and Jerry can be cogitated as violent acts according to the definitions given the scholars that have already been discussed earlier.

If the definitions of a 'slapstick comedy content' given by the experts and scholars are compared with the actions displayed and in Tom and Jerry, it will be quite transparent that the comedic violence that is displayed in Tom and Jerry are less comic and more violent. Where the experts and researchers have defined the slapstick comedy as non-harmful for the characters, Tom and Jerry has always been displaying violence rather than slapstick comedic violence which in almost all the episodes of the cartoon bring minimum harms to the characters that are involved in the actions. With an attempt to be humorous, the cartoon turns into a solid display of violent actions with weapons. Besides, the actions that Tom and Jerry claims as slapstick comedic-violence, often overlooks the definition of the comedic-violence. Although, in many cases, Tom and Jerry has maintained only a few of the traits of a slapstick comedy. The following Ven-diagram (Figure 5) presents the comparative image of the actions performed (with different equipment) by the various characters in Tom and Jerry and slapstick comedy.

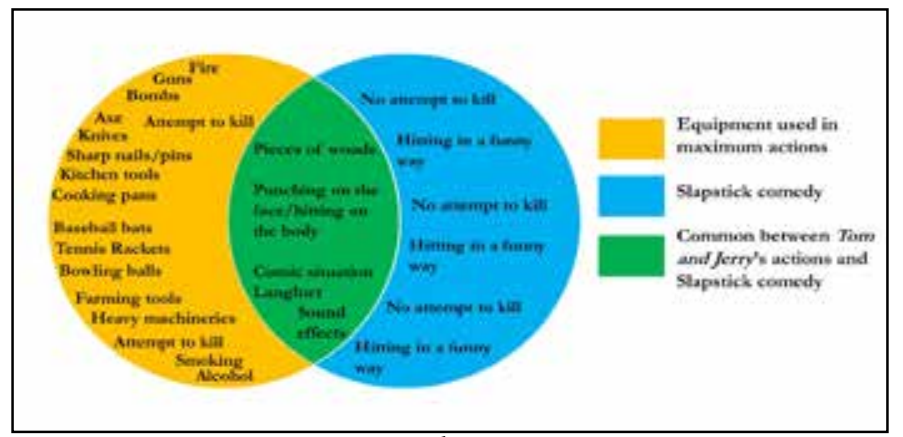

Figure 5: The Ven-diagram of Tom and Jerry's actions compared with slapstick comedy. 


\section{CONCLUSION}

It has been more than a century that animation, as a genre in visual entertainment, has been entertaining people from all ages around the globe, and within these 100 years animation industry has introduced people from all over the world with some amazing characters where Tom and Jerry would be on the very top of the mountain of success (Cavalier, 2011, p. 8). After being created during the great depression in the USA when audiences were highly depressed due to the consequence of the Second World War, Tom and Jerry started entertaining people not only in the USA but also all over the world (Byrnes, 2 August 2015). Despite having the elements of slapstick comedy, this cartoon contains numerous examples of violence which has a prior chance to have an impact on the psychology of juveniles and adolescents and since, most of the adults do not consider the cartoons with comic and humour as violent ones, the chance goes even higher for the juveniles to be affected by this projection of violence (Kirsh, 2012). Another major concern can be children's perception of television violence, as it different from that of the adults and those more acceptable to the adults (Haynes, 1978).

From the violent cartoons, juvenile viewers can assume the violence justified which can definitely have a severe impact on their learning of social behaviour and development of psychology (Simmons, et al., 1999). The local authorities regarding the TV channels all over the world should pay more attention to this issue of portrayal of violence in such a popular cartoon series. At this juncture, this study specifies the actions in Tom and Jerry which can be defined as violent ones, although juveniles and many of the viewer from the adult stage of age may might have disagreements regarding calling Tom and Jerry as a violent cartoon. It is important to define what violent in Tom and Jerry before studying the impact of violence on the viewer who have this cartoon in their watch list, because different scenes may have different impacts on the minds of children in different ways.

Hence, by not focusing on the characters but on the actions and ways to perform those, this study finds out the actions only that can be accused as violent ones and that can be impactful for the minds of the juveniles. A study on the reception of Tom and Jerry on the juveniles centering the issue of violence and a quantitative content analysis study, focusing on duration of violence in the episodes of Tom and Jerry would definitely add on some extra value with the result of this study and in future would help the scholars to establish the idea of the projection of violence by Tom and Jerry. Besides, this study would provide the documented list of violent acts in the cartoons and animations for the future animators and animation film directors have the upper hand to make their productions free from the allegations of projections of violent acts. While making or creating new contents for the visual entertainments for the children, the animators can always have this list to avoid the controversies of projecting violence.

\section{REFERENCES}

Altheide, D. L. \& Schneider, C. J. (2013). Qualitative media analysis ( $2^{\text {nd }}$ ed). Thousand Oaks, CA: Sage.

Bandura, A. (1973). Aggression: A social learning analysis. Englewood Cliffs, New Jersey: Prentice Hall.

Baley, C. \& Lenburg, J. (2009). The Encyclopedia of Animated Cartoons (3 ${ }^{\text {rd }}$ ed). New York: Facts on File. 
Beckman, J. (1997). Television violence: What the research says about its effect on young children. Winnetka, IL: Winnetka Alliance for Early Childhood.

Berg, B. L. \& Lune, H. (2014). Qualitative research method for social sciences ( $8^{\text {th }} \mathrm{ed}$ ). Essex. Pearson Education Limited.

Berkowitz, L. (1993). Aggression: Its causes, consequences and control. Philadelphia: Temple University Press.

Brion, P. (1990). Tom and Jerry: The Definitive Guide to their Animated Adventures. New York: Crown Publishers.

Bromley, P. (2019, 24 February). What is slapstick comedy?' Live About. Retrieved from https://www.liveabout.com/slapstick-comedy-definition-801516. Accessed on 10 March 2019.

Bruner, S. J. \& Postman, L. (1949). On the perception of incongruity: A Paradigm. Journal of Personality: 18, 206-223.

Bushman, B. J., \& Anderson, C. A. (2001). Media Violence and the American Public: Scientific fact versus media misinformation. American Psychologist, 56, 354-477.

Byrnes, Paul. (2, August, 2015). The real reason Tom and Jerry have lasted 75 years. Retrieved from http://www.smh.com.au/entertainment/movies/the-real-reason-tom-andjerry-have-lasted-75- years-20150728-gim91k.html accessed on 26 February, 2019.

Cavalier, Stephen. (2011). The world history of animation. Berkeley, CA: University of California Press.

Chinn, P. L. \& Krammer, M. K. (1999). Theory and Nursing: a systematic approach. St. Louis, Mosby Year Book.

Elo, S. \& Kyngas, H. (2008). The qualitative content analysis process. The Journal of Advanced Nursing. 62(1). 107- 115.

Essawy, O. (2018, 4 December). Attention, children! Tom and Jerry can make you violent! Identiti Magazine. Retrieved from https://identity-mag.com/attention-children-tomand-jerry-can-make-you-violent/ accessed on 25 February, 2018.

Feilitzen, C. V. \& Carlson, U. (Eds.) (2000). Children in the new media landscape game pornography perception. Goteborg, Goteborg University.

Gerbner, G. et al. (1978). Television violence profile no. 8. The Journal of Communication, 27(2), 171-180.

Gunter, B. (1985). Dimension of television violence. Aldershot, UK: Gower.

Haynes, R. B. (1978). Children's perceptions of "comic" and "authentic" cartoon violence. Journal of Broadcasting \& Electronic Media, 22(1), 63-70.

Islam, M. M., Adnan, H. M., Omar, M. A. M., \& Akter, N. (2020). Meaning of the colors in the portrayal of the animated characters. Malaysian Journal of Media Studies, 19 (1), 43-56.

Johnson, H. (2016, May 4). Tom and Jerry, Terrorists of the Cartoon World. Foreign Policy. https:// foreignpolicy.com/2016/05/04/tom-and-jerry-terrorists-of-the-cartoon-world/

Jones, C. (Producer) \& Jones. C. \& Washam. B. (Directors) (1966). Love Me, Love My Cat [Motion picture]. United States: Metro Golden Mayer Cartoon.

Kirsh, S. J. (2012). Children, adolescents and media violence. A critical look at the research. London: Sage. 
Krippendorff, K. (2004). Content analysis: An introduction to its methodology ( $2^{\text {nd }}$ ed). Thousand Oaks, CA: Sage.

Lauri, S. \& Kyngas, H. (2005). Developing nursing theories. Vantaa, Finland: Werner Soderstron, Dark Oy.

Mayring, P. (2004). Qualitative content analysis. A Companion to Qualitative Research, 1, $159-176$.

McCabe, C., 2021. Tom And Jerry Blamed For Violence In The Middle East - Comic Book Legal Defense Fund. [online] Cbldf.org. Available at: <http://cbldf.org/2016/05/tom-and-jerryblamed-for-violence-in-the-middle-east/> [Accessed 12 January 2021].

McNamara, J. (2005). Media Content Analysis: Its uses, benefits and best practices methodology. Asia Pacific Public Relation Journal. 6 (1) 1-34

Miles, M. B. Huberman. A. B. (1994). Qualitative data analysis. California. Sage.

Morrison, D. E. (1993). The idea of violence in A. M. Hargrave(Ed.), Violence n factual television, Annual review 1993 (pp. 124-129), London: John Library.

Neuendorf, K. A. (2002). The Content analysis guidebook. California Sage.

Peacock, L. (2014). Slapstick and comic performance: Comedy and pain. Springer.

Potter, W. J. \& Ware, W. (1987). An analysis of the context of antisocial acts on prime-time television. Communication Research, 46(4). p. 664-686

Potter, W. J. (1999). On media violence. California: Sage.

Priest, S. H. (2010). Doing media research: An introduction ( $\left.2^{\text {nd }} E d\right)$. London: Sage Publication.

Quimby, F. (Producer) \& Hanna, W. \& Barbera, J. (Directors) (1947). A Mouse in the House [Motion picture]. United States: Metro Golden Mayer Cartoon.

Snyder, W. L. (Producer) \& Deitch, G. (Directors) (1962). Calypso Cat [Motion picture]. United States: Metro Golden Mayer Cartoon.

Raghvan, Sundarsan. (2016, 4 May). Egypt official blames ‘Tom and Jerry' cartoons for violence in the Middle East. Washington Post Retrieved from https://www.washingtonpost. com/news/worldviews/wp/2016/05/04/egypt-official-blames-tom-and-jerrycartoons-for-mideast-violence/?noredirect=on\&utm_term $=.07 \mathrm{de} 74 \mathrm{f} 2 \mathrm{af} 92$ accessed on 25 February, 2018.

Schneider, M. (2012). Qualitative content analysis in practice. Los Angeles: Sage.

Sparks, G. G. (2010). Media effects research: A basic overview. Boston, Wadsworth.

Smith, S. L., Wilson, B. J., Kunkel, D., Linz, D., Potter, W. J., Colvin, C. M., \& Donnerstein, E. (1998). Violence in television programming overall: University of California, Santa Barbara study. National television violence study, Vol. 2 (pp. 5-204). Thousand Oaks, CA: Sage.

Simmons, B. J., Stalsworth, K \& Wentzel, H. (1999). Television violence and its effects on young children. Early Childhood Education Journal, 26, (3).

The Best Cartoons of All Time, (n.d.). Retrieved from https://www.ranker.com/ crowdranked-list/my-favorite-cartoons-of-all-time accessed on 27 February 2019.

Tom and Jerry top cartoon survey, (2004). BBC. Retrieved from http://news.bbc.co.uk/2/ hi/entertainment/3692108.stm accessed on 27 February 2019.

Wells, P. (1998). Understanding animation. New York: Routledge. 
Wimmer, R. D., \& Dominick, J. R. (2013). Mass media research. An introduction (10th ed). Boston: Cengage Learning. 